\title{
A Quantitative Evaluation of Metacognitive Awareness among Business Administration Students
}

\author{
Doha Al Awdah \\ Department of Business Administration- Female Branch \\ Jubail University College P O Box 10074, Jubail Industrial City 31961,KSA \\ Dr Sofia Jasmeen \\ Department of Business Administration- Female Branch \\ Jubail University College P O Box 10074, Jubail Industrial City 31961,KSA \\ Dr Asha Alexander \\ Department of Business Administration- Female Branch \\ Jubail University College P O Box 10074, Jubail Industrial City 31961,KSA
}

\begin{abstract}
Purpose - The metacognitive approach is the new learning paradigm to enrich the standard of education in general and that of business education in particular The purpose of the study was to ascertain the views and opinions of Business Administration students regarding the metacognitive awareness. Design- A self-administered questionnaire was distributed to female undergraduate students. Statements cover between two major components, including knowledge about cognition and regulation of cognition. For analyzing the hypothesis, parametric as well as non-parametric test have been used. Findings -The students had a substantial awareness of metacognition and was correlated positively and significantly with their academic performance. There was no significant difference in the metacognitive awareness of undergraduate students based on their academic levels, majors and learning styles. This significant improvement on the academic performance of the students was due to the university adherence to the domains set by the national quality framework. Students on each academic level benefited by alignment of Learning Outcomes, Assessment Methods, and Teaching Strategy and attained increasing knowledge, skills communication and information technology preparing them to be autonomous learners. Originality/Value - This paper contributes to the need for significance of metacognitive awareness among undergraduate students. The findings provide insight into students' metacognitive skills and to adopt certain teaching strategies and assessment patterns for inculcating high order thinking in the students to prepare them as autonomous learners and engage lifelong earning among them.
\end{abstract}

Key words - Metacognition, Metacognitive Awareness, Academic Levels, Academic performance, Learning Styles, Autonomous learners

\section{INTRODUCTION}

Business Administration Education in developing countries is gaining more attention and consideration due to its prominent advantages in economic, political, technological and social aspects of the country. The metacognitive approach is the new learning paradigm to enrich the standard of education in general and that of business education in particular (Bransford et al, 2000). Metacognition is the process of controlling and monitoring one's own cognition. The 
prefix 'meta' refers to thinking about thinking and it is the awareness of one's own thoughts and reflection on the thinking of the self and others (Kuhn and Dean, 2004). The paradigm shift from teacher-centered to student-centered education requires students to possess the metacognitive skills.This enhances lifelong learning which takes place outside the formal business school environment (Hannon et al, 2004; Hinton, 2005). These skills are vital assets for the manger to perform in the workplace and play a crucial role in delivery of courses in the domain of business education (Braun 2004). Cultural Metacognition is the key skill in the international business to handle complexity, communicate virtually, and work across cultures and to get the full potential of teams and networks of people. (Morris, 2012).Several studies examining the deficiencies in the level of general business decision making recommend that poor critical thinking is the main element of failing decision making (Braun, 2004; Pascarella, 1997).

Metacognitive skills which invariably includes critical thinking skills are the need of the hour. The academic institutions could play a dominant player to hone this skill among the learners. Halpern (1998) stresses that critical thinking is the most required skill at any workplace, yet there is ample evidence that many adults consistently engage in flawed thinking. Hannon et al (2004) identifies the presentation of a specific module entitled 'Critical Thinking' in the bachelor's program of business subjects. Braun (2004) converses the possibility of including the training of critical thinking skills into customary content-focused courses. The most frequently sought solution is adapting active learning approaches and incorporating the metacognitive skills in the learning method. The Harvard case study method (Braun, 2004) and problem-based learning are among the most well-known solution tools (Capon and Kuhn, 2004; Gijselaers, 1996).Metacognition is a critical part of self-learning .Today, most models of self-regulated learning consolidate parts of both metacognition and self-regulation concentrating on self-monitoring (Dinsmore, Alexander, \& Loughlin, 2008). As students become more skillful at using metacognitive strategies, they become more confident, perform better on exams and complete work more efficiently. These students are characterized as one who ask questions, take notes, and assign their time and their resources in ways that help them to be autonomous learners (Paris \& Paris, 2001)

The prominent role of metacognitive skills would, therefore, justify a strong locus in the business curriculum.The women in Saudi Arabia are encouraged to seek professional education and careers as part of the Kingdom's development plans. Building management competence is based on Islamic principles (Abdus Sattar Abbasi et al 2010, Mohammad Bagher Babaei et al 2012). The institutes use various models to develop competencies in the students (McEvoy et al, 2005). Research studies shows the presence of high managerial competencies (Asha et al, 2013) and highly entrepreneurial quotient (Asha et al, 2013) among management students. Metacognitive skills can be taught to students to improve their learning (Nietfeld \& Shraw, 2002; Thiede, Anderson, \& Therriault, 2003). It is imperative that instructors help learners develop metacognitively but the biggest challenge is to explore metacognition awareness among the students and to set tasks at an appropriate level of difficulty to make it challenging enough but not so challenging that students becomes frustrated(Biemiller \& Meichenbaum, 1992). Research problemThe nature of learning in the Middle East and particularly among Saudi students seems to be deep-rooted in memorization and recall (Rugh, 2002; Cassidy, 2003). To be self-directed, learners, need a set of skills to be developed and also an attitude. The skills must be developed to be effective and the individuals may utilize these skills, depending on the particular requirementsof a given situation. If a student's formal education consisted of his passively receiving information from his teachers, then that student's skills in monitoring and managing his ownlearning may be poorly developed, and his commitment to actively managing his own learning will be lacking. (Allison 2006). However, 
this attitude to learning can be changed with the useof teaching and assessment strategies that is focused on deep and constructive learning and facilitate the culture of self-reflection, selfregulation and self-efficacy among learners. This will help them acquire the relevant competencies needed to function optimally as managers in Saudi Arabia. The literature reveals that the training of metacognitive abilities and the assessment of these abilities is an area which is attracting a lot of attention from academicians during current times. It is very challenging for learners to be mindful about their strengths and limitations. However, in recent years, scant literature has addressed issues in assessing the level of metacognitive awareness and its relation with demographic factors. Then the primary research question of this study was, "What is the level of metacognition awareness among undergraduate business students at College of Business Administration"?

\section{RESEARCH METHODOLOGY}

Primary data were collected by self-administered questionnaire distributed to female undergraduate students of Eastern province of Saudi Arabia. The duration of the undergraduate program includes four academic years plus one academic year for the preparatory. Each academic consists of two semesters. The figure of female students pursing business administration was large in number so it was impracticable to pursue the study on hundred percent enumerative bases. The sample included representation from freshmen (firstyear college students), sophomores (second-year college students), juniors (third-year college students) and seniors (fourth-year college students). The questionnaire was distributed to 250 respondents and response were received from 190 respondents. The empirical studies related to metacognition assessment are built primarily on the observation of students solving problems or in thinking aloud sessions. A variety of self-scoring instruments are now available to assess the metacognitive abilities of university students. The present research uses the selfscoring instrument that is metacognitive awareness inventory (MAI) (Schraw and Dennison) and aims to add to the sparse literature on assessing the level of students' metacognitive awareness. It further aims to find if metacognitive awareness is correlated with the student's (a) academic performance (b) academic levels (c) learning styles and (d) majors.

The questionnaire comprised of two parts. In the first section the respondents provided demographic information along their academic level, major, cumulative GPA and getting a line mode. Academic levels were freshmen, sophomores, juniors and seniors. Two options on major were provided, namely Business (BUS) and Management Information Systems (MIS). Cumulative GPA included five ranges, first is below 2 referred to as underperforming students. The second category is between 2.00 to 2.49 and the third was between 2.50 and 2.99 . The average students fall under the second and third category. The fourth category of GPA is between 3.00 and 3.49 categorized as excellent. While the fifth range, which falls between 3.5 and 4 is regarded as exceptional. The learning styles category included visual, auditory, kinesthetic and mixed style. Visual learners do learn best through seeing and observing, auditory learns best through listening, kinesthetically learn best while doing, touching and moving while mixed learners those whom are adaptable to any learning situation. A learning style questionnaire developed by the British Council was circulated to students at the start of each semester in which have made students aware of their style of learning.

The second part of the questionnaire was built from metacognitive awareness inventory (MAI) (Schraw, G. \& Dennison, R.S. (1994). It encompasses 24 statements based on the five point Likert scale ranging from strongly agree to strongly disagree. Statements covers between two major components, including knowledge about cognition and regulation of cognition (Brown, 1987; Flavell, 1987; Jacobs \& Paris, 1987). Knowledge about cognition includes three sub 
processes that facilitate the reflective aspect of metacognition: declarative knowledge (knowledge about self and strategies), procedural knowledge (knowledge about how to use strategies), and conditional knowledge (knowledge about when and why to use strategies). Regulation of cognition includes a number of sub processes that facilitate the control aspect of learning. Five component skills of regulation includes Planning (goal setting, and allocating resources prior to learning), Information Management Strategies (Skills and strategy sequences used to process information more efficiently including organizing, elaborating, summarizing, selective focusing),Comprehension Monitoring (assessment of one's learning or strategy use),Debugging Strategies( strategies used to correct comprehension and performance errors)and Evaluation ( analysis of performance and strategy effectiveness after a learning episode) (Artzt\& Armour-Thomas, 1992; Baker, 1989). Data preparation begins with preliminary check of the entire filled up questionnaire for its completeness. The collected data was edited, coded, tabulated, grouped and organized according to the requirement of the study and then entered into SPSS (Statistical package for social sciences) for analysis. The Cronbach's Alpha test was run to estimate the reliability of questionnaire items, Descriptive Statistics such as mean, standard deviation, frequencies were used to summarize and describe the basic features of data, Pearson Product-Moment Correlation test was used to measure the strength of a linear correlation between variables, One-Way Analysis of Variance (ANOVA) and T Test was used to further analyze the data. To achieve the stated objectives, the following hypotheses were framed:

Ho1: There is no significant difference in the metacognitive awareness of students based on their academic performance

Ho2: There is no significant difference in the metacognitive awareness of students based on their academic levels

Ho3: There is no significant difference in the metacognitive awareness of students based on their learning styles

Ho4: There is no significant difference in the metacognitive awareness of students based on their majors

\section{ANALYSIS AND INTERPRETATION OF DATA}

The primary data were analyzed using Statistical Package for the Social Sciences (SPSS 16.0). The students' level of metacognitive awareness was determined by the analysis of the results of the questionnaire.

Reliability Test: Cronbach's Alpha for Internal Consistency: Cronbach's alpha coefficient was run to determine the reliability of the questionnaire items of knowledge and regulation. Cronbach's alpha ranges between 0 and 1. The closer Cronbach's alpha coefficient is to 1 the greater the internal consistency of items in the scale. To determine the reliability of each group of items, George and Mallery (2003) developed the following rules of thumb: $>0.90=$ Excellent, $0.80-0.89=$ Good, $0.70-0.79=$ Acceptable, $0.60-0.69=$ Questionable, $0.50-0.59=$ Poor and < $0.50=$ Unacceptable. The value of alpha coefficient of knowledge and regulation items which are 0.80 and 0.81 respectively, suggesting that the items have a good internal consistency. Hence, it can be concluded that the questionnaire is reliable.

Descriptive Analysis: Table 1 shows the descriptive statistics of the eight sub-categories of metacognition. It describes basic features of the data in a meaningful way. Mean score is the average of a data set whereas standard deviation is dispersion of a set of data from its mean. It clearly shows that the mean score of the eight sub-scales are above the mid-point on a fivepoint Likert scale. The mean score is highest in both debugging which is equal to 3.98 and conditional knowledge which is equal to 3.97 and lowest in monitoring and procedural 
knowledge which are equal to 3.72. The mean score of knowledge and regulation are very close. Students overall metacognitive awareness was calculated as 3.86 which is above the mid-point on a five point Likert scale. It can be concluded that the level of metacognitive awareness of the students was high.

Table 1: Descriptive Statistics of Subscales of Metacognition

\begin{tabular}{|l|l|l|l|}
\hline & Mean & Std. Deviation & Variance \\
\hline Declarative Knowledge & 3.924 & .578 & .334 \\
Procedural Knowledge & 3.721 & .665 & .442 \\
Conditional Knowledge & 3.974 & .894 & .798 \\
Planning & 3.747 & .702 & .493 \\
Information Management & 3.945 & .594 & .353 \\
Monitoring & 3.719 & .606 & .368 \\
Debugging & 3.977 & .578 & .334 \\
Evaluation & 3.897 & .689 & .475 \\
\hline Knowledge & 3.873 & .587 & .344 \\
Regulation & 3.857 & .473 & .224 \\
Metacognition & 3.861 & .473 & .224 \\
\hline
\end{tabular}

Correlation: A Pearson product correlation was run to determine the relationship between students' awareness of the eight sub factors of metacognition and their academic performance as demonstrated by cumulative GPA. The closer the number is to 1 the stronger the relationship. A plus sign means a positive correlation while a minus sign means a negative correlation. Table 2 shows Pearson's $r$ and it is $(+)$ between all of the sub-scales of metacognition and GPA. Hence, there is a positive relationship between the eight subscales of metacognition and cumulative GPAs of the respondents. Furthermore, the p-value indicates a significant correlation. Hence it is inferred that there is a significant positive correlation between the eight subscales of metacognition and respondents' GPAs. A Pearson product correlation was run to determine the relationship between students' awareness of the two components of metacognition in relation to their academic performance. Knowledge and regulation overall and their correlation with respondents GPAs were calculated. 
Table 2: Correlations between Subscales of Metacognition and GPA

\begin{tabular}{|l|l|l|l|l|l|l|l|l|}
\hline & $\begin{array}{l}\text { Declarative } \\
\text { Knowledge }\end{array}$ & $\begin{array}{l}\text { Procedural } \\
\text { Knowledge }\end{array}$ & $\begin{array}{l}\text { Conditional } \\
\text { Knowledge }\end{array}$ & Planning & $\begin{array}{l}\text { Information } \\
\text { Management }\end{array}$ & Monitoring & Debugging & Evaluation \\
\hline $\begin{array}{l}\text { Procedural } \\
\text { Knowledge }\end{array}$ & $.616^{* *}$ & & & & & & & \\
\hline $\begin{array}{l}\text { Conditional } \\
\text { Knowledge }\end{array}$ & $.463^{* *}$ & $.483^{* *}$ & & & & & & \\
\hline Planning & $.554^{* *}$ & $.563^{* *}$ & $.467^{* *}$ & & & & & \\
\hline $\begin{array}{l}\text { Information } \\
\text { Management }\end{array}$ & $.569^{* *}$ & $.542^{* *}$ & $.326^{* *}$ & $.384^{* *}$ & & & & \\
\hline Monitoring & $.475^{* *}$ & $.547^{* *}$ & $.429^{* *}$ & $.526^{* *}$ & $.477^{* *}$ & & & \\
\hline Debugging & $.479^{* *}$ & $.364^{* *}$ & $.272^{* *}$ & $.341^{* *}$ & $.547^{* *}$ & $.329^{* *}$ & & \\
\hline Evaluation & $.613^{* *}$ & $.488^{* *}$ & $.498^{* *}$ & $.513^{* *}$ & $.469^{* *}$ & $.471^{* *}$ & $.379^{* *}$ & \\
\hline GPA & $.313^{* *}$ & $.274^{* *}$ & $.186^{*}$ & $.249^{* *}$ & $.265^{* *}$ & .131 & $.273^{* *}$ & $.263^{* *}$ \\
\hline
\end{tabular}

Table 3 shows Pearson's $r$ for the correlation between knowledge and GPA which is 0.301, regulation and GPA is 0.317. Therefore, the value of $\mathrm{r}$ is positive in both correlations. Furthermore, $\mathrm{p}$-value $=0.001$, indicates that the correlation is significant at the level 0.01 . Hence it is inferred that there is a significant positive correlation between respondents' knowledge and regulation of metacognition and their GPAs. Thus, alternative hypothesis is accepted and there is a significant correlation between students' metacognitive awareness and their academic performance. The significant positive relationship between student's academic performance and metacognitive awareness .has likewise been demonstrated in studies conducted by Sawhney and Bansal (2015) in undergraduate students.

Table 3: Correlations between Knowledge, Regulation and GPA

\begin{tabular}{|l|l|l|}
\hline & Knowledge & Regulation \\
\hline Regulation & $.768^{* *}$ & \\
\hline GPA & $.301^{* *}$ & $.317^{* *}$ \\
\hline
\end{tabular}

One-Way ANOVA: A one- way analysis of variance (ANOVA) was calculated on students' metacognitive awareness to their academic levels. Table 4 shows, $F(3,186)=1.45, p=0.229>$ 0.05 (chosen level of significance). Hence it is inferred that there is no significant difference in the metacognitive awareness of students based on their academic levels. Thus, null hypothesis is accepted and there is no significant difference in students' metacognitive awareness among different academic levels while Khezrlou (2012) finding of one-way ANOVA indicated learners' preferences for the metacognition strategies varied across different levels of education.

Table 4: One-way ANOVA of Metacognition and Academic Levels

\begin{tabular}{|l|l|l|l|l|l|}
\hline & Sum of Squares & df & Mean Square & F & Sig. \\
\hline Between Groups & .968 & 3 & .323 & 1.453 & .229 \\
Within Groups & 41.304 & 186 & .222 & & \\
Total & 42.272 & 189 & & & \\
\hline
\end{tabular}

A one-way analysis of variance (ANOVA) test was performed on students' metacognitive awareness of objection to their learning styles. Table 5 shows, $F(3,186)=0.95, p=0.416>0.05$ (chosen level of significance). Hence it is inferred that there is no significant difference in the 
metacognitive awareness of students based on their learning styles. Thus, null hypothesis is accepted and there is no significant difference in students' metacognitive awareness based on their learning styles Steven Shannon (2008) carried out research project to determine metacognitive strategies for specific learning styles to create self-directed learners.

Table 5: One-Way ANOVA of Metacognition and Learning Styles

\begin{tabular}{|l|l|l|l|l|l|}
\hline & Sum of Squares & df & Mean Square & F & Sig. \\
\hline Between Groups & .640 & 3 & .213 & .954 & .416 \\
Within Groups & 41.631 & 186 & .224 & & \\
Total & 42.272 & 189 & & & \\
\hline
\end{tabular}

T test: Table 6 shows metacognition mean scores of BUS and MIS majors of respondents. The mean score of MIS 3.90 is slightly higher than of BUS which is 3.84.

Table 6: Group Statistics of Metacognition among BUS and MIS

\begin{tabular}{|c|c|c|c|c|}
\hline & Major & $\mathrm{N}$ & Mean & Std. Deviation \\
\hline \multirow[t]{2}{*}{ Metacognition } & BUS & 123 & 3.836 & .458 \\
\hline & MIS & 67 & 3.907 & .499 \\
\hline
\end{tabular}

Table 7 shows Independent Sample T Test between BUS and MIS Majors. An independent samples test was run to determine whether the metacognition of MIS and BUS majors are significantly different. Indicates p-value $=0.419>0.05$ (chosen level of significance); thus, the upper set of figures will be considered (equal variances are assumed). Hence it is inferred that there is no significant difference in the metacognitive awareness of students based on their major. Both BUS and MIS students are equally aware of their own metacognitive manners. Thus, null hypothesis is accepted and there is no significant difference in students' metacognitive awareness based on their majors while Dirk Tempelaar (2006) in his empirical analysis, finds strong differences in the relationship between metacognition and course performance for different types of subjects.

Table 7: Independent Sample T Test between BUS and MIS Majors

\begin{tabular}{|l|l|l|l|l|l|l|l|}
\hline & \multicolumn{2}{|l|}{ Levene's Test for Equality of Variances } & \multicolumn{4}{l|}{ t-test for Equality of Means } \\
\cline { 2 - 8 } & F & Sig. & t & df & Sig. (2-tailed) & Mean Difference \\
\hline $\begin{array}{l}\text { Equal variances assumed } \\
\text { Equal variances not assumed }\end{array}$ & .656 & .419 & -.998 & 188 & .320 & -.07163 \\
& & & -.972 & 126.01 & .333 & -.07163 \\
\hline
\end{tabular}

\section{DISCUSSION}

In recent years, business education has garnered much attention due to widespread research that has been conducted in management education on developing competencies for competitiveness in management students (Asha Alexander 2015), measuring entrepreneurial quotient(Asha Alexander and Areej Al Shamrani.(2013a), measuring managerial competencies in management program. (Asha Alexander and Farah A. Al-Moaibed .(2013b) need analysis for the human resource management program (Asha Alexander and Ghadah Al Saleh (2015) and exploring factors for improving career fair experience for management students (Asha Alexander and Ghadah Al Saleh, 2016) but insufficient literature has addressed issues on metacognition awareness among business administration students in Saudi Arabia. The present study was confined only to female Business Administration students in the eastern province of Saudi Arabia. Moreover, the study was restricted to 190 undergraduate students; a 
larger sample can be taken up in future research to comprise all colleges of Saudi Arabia for further study. The results obtained in this study suggest that students had substantial awareness and control over their thinking and that there is a positive correlation between students' awareness of metacognition and their academic performance and there is no significant difference in the metacognitive awareness among freshmen, sophomores, juniors and seniors. Hence, students from the four different academic levels disclose similar metacognitive awareness. Additionally, findings with regard to the majors reveal that there is no significant difference in the metacognitive awareness between Business students and Management Information Systems students based on their majors. Furthermore, the findings of this study relating to the learning style disclose that there is no difference in the metacognitive awareness among visual, auditory, kinesthetic and mixed learners. This may be due to learners adopt different styles of learning for Different course requirements. There is no significant difference in the metacognitive awareness of undergraduate students based on their learning styles. Recent studies have also indicated that metacognitive aware learners are more strategic and perform better than unaware learners (Garner \& Alexander, 1989; Pressley \& Ghatala, 1990).The significant improvement in the academic performance of the students and awareness of metacognition skill in present study was due to the adherence of curriculum to the domains set by the national qualifications framework (NQF) at Saudi Arabia Students Learning Outcomes,

Assessment Methods, and Teaching Strategy are aligned between student learning and teaching and aim of stimulating higher order thinking of students. The learning domains are Knowledge, Cognitive Skills, Interpersonal Skills \& Responsibility, Communication and Information Technology. Simpson and Nist (2000) emphasize that instructors need to provide explicit instruction on the use of study strategies. Differentiated teaching strategies are selected in present study to align with the curriculum taught, the needs of students, and the intended learning outcomes. Teaching methods include: lecture, debate, small group work, whole group and small group discussion, research activities, lab demonstrations, projects, debates, role playing, case studies, guest speakers, memorization, humor, individual presentation, brainstorming, and a wide variety of hands-on student learning activities Therefore, a module on enhancing metacognitive skills can be planned and mapped with courses' learning outcomes which will further improve students' knowledge and regulation of their cognition and helps them to be autonomous learners. The instructors can guide the students to become strategic thinkers by encouraging students to preset questions in that spans three phases of metacognition in the learning task namely planning, monitoring and evaluating phase (Fogarty, 1994).

\section{CONCLUSION}

Business educators are entrusted with the task of accomplishing critical thinking and selfdirected learning among the students.The high metacognition awareness among the students in the present study is an evidence to the fact that the students possesses these vital skills and the delivery of courses in the domain of business education was very successful from teacher centered to student-centered education thereby enriching the standard of business education. Developing metacognitive awareness is important to the instructors as well as it will further help them to guide learners to become strategic thinkers by creating right challenging and motivating environment .It helps the learners to be more conscious about what they are learning and engage in lifelong learning,

\section{References}

Abdus Sattar Abbasi, Kashif Ur Rehman and Amna Bibi. (2010). Islamic management model African Journal of Business Management Vol. 4(9), pp. 1873-1882, 4 August, 2010 
Allison A. preparing our graduates for a lifetime of learning (2006).American Journal of Pharmaceutical Education, Volume 70 Issue1.

Artzt, A. F., and Armour-Thomas, E. (1992). Development of a cognitive-metacognitive Framework for protocol analysis of mathematical problem solving in small groups. Cognition and Instruction, 9(2), 137-175.

Asha Alexander. (2015).Developing Competencies for competitiveness in Management. Paperback, Scholar Press, 9th April 2015.

Asha Alexander and Areej Al Shamrani.(2013a).Entrepreneurial Quotient: A Strategic Asset for Personal Branding" ,European Journal of Social Sciences Volume 38, Number 2.Journal of International Education in Business

Asha Alexander and Farah A. Al-Moaibed. (2013b).Measuring Managerial Competencies in Management Program, European Journal of Business and Management .Volume 5, Number 11.

Asha Alexander and Ghadah Al Saleh. (2015).The Three fold Need Analysis for the Human Resource Management Program .International Journal of Management Sciences. Volume 5, Number 2, page147-154.

Asha Alexander and Ghadah Al Saleh. (2016).Exploring Factors for Improving Career Fair Experience for Management Students, European Journal of Business and Management, Volume 8, Number.4.

Baker, L. (1989). Metacognition, comprehension monitoring, and the adult reader. Educational Psychology Review, 1(1), 3-38.

Biemiller, A., and Meichenbaum, D. (1992). The nature and nurture of the self-directed learner. Educational Leadership, 50, 75-80.

Bransford, J.D., A. L. Brown, and R.R. Cocking, (2000). How people learn: brain, mind, Experience, and school, Washington, D.C.: National Academy Press, 206-230.

Braun, N.M. (2004).Critical thinking in the business curriculum, Journal of Education for Business, Vol 79, No 4, pp 232-236.

Brown, A. L. (1987). Metacognition and other mechanisms. In F. E. Weinert and R. H. Kluwe (Eds.), Metacognition, motivation and understanding (pp. 65-116). Hillsdale, NJ: Erlbaum

Capon, N., and Kuhn, D. (2004).What's so good about Problem-based learning? Cognition and Instruction, Volume 22, Number 1, page 61-69.

Cassidy, T.J., (2003). Education in the Arab states: preparing to compete in the global economy. In: Schwab, Klaus, Cornelius, Peter (Eds.), the Arab World Competitiveness Report, World Economic Forum, Geneva, page. 218-234

Dirk T. Tempelaar. (2006).The role of metacognition in business education, Industry and Higher Education October 2006, page 291-297

Dinsmore, D. L., Alexander, P. A., and Loughlin, S. M. (2008). Focusing the conceptual lens on metacognition, selfregulation, and self-regulated learning. Educational Psychology Review, 20, 391-409.

Flavell, J. H. (1987). Speculations about the nature and development of metacognition. In F. E. Weinert \& R. H. Kluwe (Eds.), Metacognition, motivation and understanding (pp. 21-29). Hillsdale, NJ: Erlbaum Learning Network Meeting, OECD, Paris,

Fogarty, R. (1994). How to teach for metacognition. Palatine, IL: IRI/Skylight Publishing.

Garner, R., and Alexander, P. A. (1989). Metacognition: Answered and unanswered questions, Educational psychologist, 24 (2), 143-158.

George, D., \& Mallery, P. (2003). SPSS for Windows step by step: A simple guide and reference 11.0 update (4th Ed.). Boston: Allyn \& Bacon.

Gijselaers, W.H. (1996).Connecting problem-based practices with educational theory, New Directions for Teaching and Learning, Volume 68, page 13-21.

Halpern, D.F. (1998).Teaching critical thinking for transfer across domains: dispositions, skills, structure training, and Metacognitive monitoring, American Psychologist, Volume 53, No 4, page 449-455. 
Hannon, S., McBride, H., and Burns, B. (2004).Developing creative and critical thinking abilities in business graduates: the value of experiential learning techniques, Industry and Higher Education, Volume 18, No 2, page 95-100.

Hinton, C.D. (2005), Learning Sciences and Brain Research: Report of the Third Lifelong Learning Network Meeting, OECD, Paris,

Jacobs, J. E., \& Paris, S. G. (1987). Children's metacognition about reading: Issues in definition, measurement, and instruction. Educational Psychologist, Volume 22 Issue 3 and 4, page 235-278.

Khezrlou, S. (2012, April). The Relationship between Cognitive and Metacognitive Strategies, Age, and Level of Education. The Reading Matrix, 12, 50-61.

Kuhn, D., and Dean Jr, D. (2004).Metacognition: a bridge between cognitive psychology and educational practice, Theory into Practice, Volume 43, No 4, page 268-273.

McEvoy, G.M.; Hayton, J .M; Warnick, A.P.; Mumford, T.V; Hanks, S.H.; and Blahna, M.J. (2005). “A CompetencyBased Model for Developing Human Resource Professionals” Journal of Management Education 2005; $29 ; 383$.

Michael W. Morris, (2012), “Metacognition: The Skill Every Global Leader Needs”, Harvard Business review.

Mohammad Bather Babaei, Qader Vazifeh Damirchi, Saeed Sharifi. (2012). Analysis of Cultural Management Competencies with Emphasis on the Islamic Perspective Singaporean Journal of Business Economics, And Management Studies Vol.1, No.4, 2012

Nietfeld, J. L., \& Shraw, G. (2002). The effect of knowledge and strategy explanation on monitoring accuracy. Journal of Educational Research, 95, 131-142.

Paris, S.G and Paris, A.H. (2001).Educational Psychologist, Classroom Applications of Research on Self-Regulated Learning, 36(2), 89-101

Pascarella, P. (1997).The secret of turning thinking into action, Management Review, Volume 86, No 5, page 3839.

Pressley, M., and Ghatala, E. S. (1990). Self-regulated learning: Monitoring learning from text. Educational Psychologist, Volume 25, page 19-33.

Rugh W.A. (2002).Arab education: tradition, growth, and reform. The Middle East Journal, 56(3), page 396-414.

Schraw, G., and Dennison, R. (1994). Assessing metacognitive awareness. Contemporary Educational Psychology, Volume 19, page 460-475

Sawhney, N., \& Bansal, S. (2015). Metacognitive Awareness of Undergraduate Students in Relation to their Academic Success. The International Journal of Indian Psychology, 3(1), 1-8.

Shannon.S.V. (2008). Using Metacognitive Strategies and Learning Styles to Create Self-Directed Learners Institute for Learning Styles Journal, Volume 1, fall 2008 page 14-28

Schraw, Gregory and Moshman, David. (1995).Metacognitive Theories, Educational Psychology Papers and Publications. Paper 40

Simpson, M. L., \& Nist, S. L. (2000). An update on strategic learning: It's more than textbook Reading strategies. Journal of Adolescent \& Adult Literacy, 43(6), 528-541.

Thiede, K. W., Anderson, M. C., \& Therriault, D. (2003). Accuracy of metacognitive monitoring affects learning of texts. Journal of Educational Psychology, 95, 66-73. 